\title{
Relevance of open magnetic resonance imaging position (sitting and standing) to quantify pelvic organ prolapse in women
}

\author{
Marwa Abdulaziz'; Alex Kavanagh²; Lynn Stothers ${ }^{3}$; Andrew Macnab ${ }^{2,3}$ \\ ${ }^{1} \mathrm{PhD}$ Candidate, Department of Experimental Medicine, Department of Urological Sciences, University of British \\ Columbia, Vancouver, BC, Canada; ${ }^{2}$ Department of Urologic Sciences, University of British Columbia, and \\ Principal Investigator, International Collaboration on Repair Discovery (ICORD), Blusson Spinal Cord Centre, \\ Vancouver, BC, Canada; ${ }^{3}$ Stellenbosch Institute for Advanced Study, Wallenberg Research Centre at Stellenbosch \\ University, Stellenbosch, South Africa
}

Acknowledgements: Canadian Urologic Association (Alex Kavanagh)

Cite as: Can Urol Assoc J 2018 June 8; Epub ahead of print. http://dx.doi.org/10.5489/cuaj.5186

Published online June 8, 2018

$* * *$

\section{Abstract}

Introduction: In pelvic organ prolapse (POP), posture and gravity impact organ position and symptom severity. The advanced magnet configuration in open magnetic resonance imaging (MRO) allows patients to be imaged when sitting and standing, as well in a conventional supine position. This study evaluated if sitting and standing MRO images are relevant as a means of improving quantification of POP because they allow differences in organ position not seen on supine imaging to be identified.

Methods: Forty women recruited from a university urogynecology clinic had MRO imaging (0.5 T scanner) with axial and sagittal T2-weighted pelvic scans obtained when sitting, standing, and supine. Pelvic reference lines were used to quantify the degree of POP, and the relevance of imaging position on the detection of POP compared.

Results: Images from 40 participants were evaluated (20 with POP and 20 asymptomatic controls). Our results indicate that the maximal extent of prolapse is best evaluated in the standing position using $\mathrm{H}$ line, $\mathrm{M}$ line, mid-pubic line, and perineal line as reference lines to determine POP.

Conclusions: MRO imaging of symptomatic patients in a standing position is relevant in the quantification of POP. Compared with supine images, standing imaging identifies that greater levels of downward movement in the anterior and posterior compartments occur, presumably under the influence of posture and gravity. In contrast, no appreciable benefit was afforded by imaging in the sitting position, which precluded use of some reference lines due to upward movement of the anorectal junction. 


\section{Introduction}

The pelvic floor is a complex anatomic and functional structure that is integral to the support of the pelvic organs, maintenance of fecal and urinary continence and for normal coordination of relaxation during defecation and urination. The structural components of the pelvic floor are the endopelvic fascia and ligaments, the pelvic diaphragm, and the urogenital diaphragm. ${ }^{1}$

The pelvic diaphragm incorporates four muscles groups: the levator ani muscle comprising the puborectalis, the pubococcygeus muscle, the iliococcygeus muscle, and the ischiococcygeus muscle. ${ }^{1}$ The soft tissues of the pelvic floor include the endopelvic fascia, the levator ani muscles, the perineal membrane, the external anal sphincter, and the external genital or perineal muscles. ${ }^{2}$ Functionally, the pelvic floor muscles combine sphincteric, supportive, and sexual actions. ${ }^{3}$ The PFM have ability to contract voluntarily. ${ }^{4}$ Contraction results in elevation and closure of all soft tissues of the pelvic floor and occlusion of the pelvic hiatus to resist descent forces through the pelvis. ${ }^{3}$

Loss of integrity of these supportive structures can cause urinary and fecal incontinence, pelvic organ prolapse (POP) with descent of the anterior vaginal wall (cystocele), posterior vaginal wall (rectocele), and vaginal apex (enterocele, vaginal vault, or uterus). ${ }^{5,6}$ Failure in one compartment is most often combined with disorders in other compartments. ${ }^{7-10}$

The pathogenesis of POP is complex, with multifactorial causes involved; these include age, menopausal status, pregnancy, vaginal delivery, previous hysterectomy, chronic cough, chronic constipation, congenital factors, and obesity. ${ }^{7,8}$ Vaginal delivery is by far the most robustly associated factor, with over $90 \%$ of patients with prolapse being parous. ${ }^{11}$ The proper staging of POP is essential for appropriate clinical care and accurate outcome studies. ${ }^{12}$ Clinical examination alone is not sufficient to identify POP, particularly in the case of posterior vaginal wall prolapse or a multi-compartment problem. ${ }^{13}$

Additional entities used in the diagnosis and staging of POP include dynamic magnetic resonance imaging (MRI), ${ }^{14}$ which allows quantification of the degree of POP by relating pelvic organ descent to reliable anatomic landmarks. ${ }^{15,16}$ Other benefits are the lack of ionizing radiation and the clearer anatomical details of the soft tissue, such as muscles and pelvic viscera. ${ }^{17}$ However, the lack of a standardized protocol for MRI grading of POP makes it difficult to relate clinical and MRI staging, which complicates clinical care. ${ }^{18}$

Also, MRI assessment of POP has been restricted by the closed architecture of conventional MR technology which limits patient positioning to the horizontal plane. ${ }^{19}$ With the recent advent of open magnetic resonance imaging (MRO), imaging in different positions including sitting and standing in addition to supine allows multiplane imaging of all three compartments and observation of their reciprocal relationships. Hence, MRO provides superior visualization of the pelvic organs and musculofascial supportive structures. ${ }^{20}$

Previous studies have reported that patient position affects the degree of POP observed on clinical examination. Barber et al. ${ }^{22}$ noted that the degree of prolapse manifested in the dorsal lithotomy position corresponds well with a $45^{\circ}$ upright quantification in a birthing chair. 


\section{Abdulaziz et al Open MRI for pelvic organ prolapse}

However, a greater extent of prolapse was observed in the upright position. A comparable finding was reported in a separate study. ${ }^{23}$ Also, Visco et al. ${ }^{24}$ reported a much greater degree of prolapse in the standing examination as compared with the supine lithotomy position. ${ }^{25}$ Swift and Herring $^{26}$ made a comparison of POP quantification method assessments in the standing and lithotomy positions, and found that there was no statistical significant difference between the stages or any of the quantification POP measured method points in the dorsal lithotomy and standing orientations. ${ }^{25}$

The purpose of this study was to use MRO to determine the anatomic differences in pelvic floor anatomy that occur in POP in relation to the position of the subject, by comparing imaging when sitting and standing to supine images, and relating organ position to validated reference lines. The hypothesis was that imaging in the standing and sitting position would identify POP not apparent in the supine position due to the effect of posture and gravity on the pelvic organs.

\section{Methods}

A prospective study, carried out in the Department of Experimental Medicine and Department of Urological Sciences, University of British Columbia, Vancouver. Ethical approval was obtained from Vancouver Coastal Health (ethical review \#V14-03507). The study cohort was recruited from the urogynecology clinic and included women presenting with symptoms of POP and asymptomatic controls. All subjects signed informed consent and completed a screening sheet for metal devices; patients were included only if they were willing to be available for the time required for imaging. All medical charts were reviewed; clinical data, including symptoms of pelvic floor dysfunction and pelvic organ prolapse staging using the pelvic organ prolapse quantification system (POP-Q) were noted (POP-Q measurements were performed under the supervision of a urogynecologist). The MRO imaging protocol did not require oral or intravenous contrast agents, nor bowel preparation; all subjects emptied their bladder prior to entering the scanner.

MRO imaging scans of the pelvis were obtained with patients positioned in the scanner when supine, sitting, and standing (Fig. 1). The source MR images were obtained in the axial and sagittal plane. Parameters used were: Sagittal FSE9, FOV $=30 \mathrm{~cm} \times 30 \mathrm{~cm}$, Slice thickness $=10 \mathrm{~mm}$, Gap $=1 \mathrm{~mm}$, Number of slices $=5, \mathrm{NEX}=1, \mathrm{TE}=120 \mathrm{~ms}$, TR=2500 ms and acquisition time $=1 \mathrm{~m} 50 \mathrm{~s}$. Axial T1 GFE pelvis images, FOV $=24 \mathrm{~cm} \times 24 \mathrm{~cm}$, Slice thickness $=5 \mathrm{~mm}$, Gap $=1 \mathrm{~mm}$, Number of slices $=40$, Theta $=0$ deg, Phi $=0$ deg, $\mathrm{NEX}=1$, Flip angle $=80 \mathrm{deg}, \mathrm{TE}=$ $10 \mathrm{~ms}, \mathrm{TR}=470 \mathrm{~ms}$, and Acquisition time $=3 \mathrm{~m} 15 \mathrm{~s}(\mathrm{x} 2)$. To address the risk of fainting or dizziness during the standing scan we applied a deep venous thrombosis external pneumatic compression device around the legs of all patients scanned (Fig. 2), and used a protocol that limited the time required for image capture in each position to two minutes. After the MR imaging was completed, the images were electronically transmitted to a workstation (RHNH, VCHRI, MRO Storage at UBC) for model generation. 
Reference lines

The reference lines used to assess POP are shown in Fig. 3. Pubococcygeal line (PCL) measurements for each examination were performed by drawing a midsagittal line from the inferior margin of the symphysis pubis to the last joint of the coccyx. ${ }^{27,28}$ We also used an $\mathrm{H}$ line (HL), a straight line between the inferior rim of the pubic and posterior wall of the anal canal on the level of the impression of the puborectal sling; ${ }^{29,30}$ a perineal line (PL), a line from the internal surface of the symphysis pubis down to the caudal end of the external anal sphincter; ${ }^{14} \mathrm{a}$ mid-pubic line (MPL), a line drawn through the longitudinal axis of the pubic bone and passing through its midequatorial point; ${ }^{14,31}$ and an $\mathrm{M}$ line (ML) drawn as a vertical line extending perpendicularly from PCL to the posterior limit of $\mathrm{H}$ line. ${ }^{32}$ The SCIPP line extends from the posterior surface of the pubis to the junction between the fifth sacral and first coccygeal bone. ${ }^{33}$

Anatomical landmarks and clinical measurement points

The MRO images taken in a supine, sitting, and standing position were assessed for POP with reference to anatomical landmarks in three pelvic compartments using the previously mentioned reference lines. The three pelvic compartments are identified based on anatomical landmarks: the most posterocaudal point of the bladder base (anterior compartment), the most anterocaudal point of the cervix or vaginal vault (middle compartment), and the anorectal junction and the most anterocaudal point of the anterior rectal wall (posterior compartment). The perpendicular distances from each reference line to these three different points were assessed using PCL. If the anatomical landmark is located above a reference line, the distance has a negative value; below the reference line it has a positive value. ${ }^{34}$

Image analysis

Image analysis was done with Radiant software. All images were analyzed by the same examiner, who was blinded to group status. Image analysis was based on all sagittal source images for the comparison of length of the pelvic reference lines between the patient group and control group (PCL, SCIPP, pubopromontoreal (PP), HL, ML, MPL, and PL) in the supine, sitting, and standing positions.

Perpendicular distances between the PCL and the bladder base, vaginal apex, and anorectal junction were used to grade the degree of downward descent in the anterior, middle, and posterior compartments, respectively. In the supine position with respect to the PCL, the grading system used suggests severity as mild, moderate, and severe. Degree of prolapse below the PCL by $3 \mathrm{~cm}$ or less was graded as mild, between 3 and $6 \mathrm{~cm}$ as moderate, and more than $6 \mathrm{~cm}$ as severe. Also, the distance from each of the anatomical landmarks mentioned above to the PCL was measured in the standing position. A rectocele is graded as follows: absent (displacement inferior to the PCL of less than $1 \mathrm{~cm}$ ); mild (displacement of 1-2 cm); moderate (displacement of 2-4 cm); and severe (displacement of more than $4 \mathrm{~cm}$ ) 12 


\section{Abdulaziz et al Open MRI for pelvic organ prolapse}

\section{Results}

Forty women, 20 with organ prolapse and 20 asymptomatic controls, were recruited and underwent MRO. Table 1 summarizes their clinical data (age, parity, mode of delivery, prior surgery, symptoms and body mass index). Comparison data from applying the pelvic reference lines on midsagittal MRO images in women with and without POP when imaged standing, supine and sitting are summarized in Tables 2, 3 and 4 respectively.

The standing image data (Table 2 and Fig. 4) show significant differences in the mean lengths of PCL, SCIPP, HL, ML, MPL, and PL between the control group and the POP group. However, the PP line measurement was not significantly different between the two groups. The differences between the women with and without prolapse were predominantly evident in the standing position.

The images taken in the supine position (Table 3 and Fig. 5) used the HL, ML, MPL, PP, and PL measurements; the increases in mean lengths between the two groups were statically significant. However, the PCL, and SCIPP line of each reference remained stable with no significant change in length between the control group and POP group.

Table 4 and Fig. 6 show that there were no statistical differences in the sitting position for PCL, SCIPP, MPL, and PL between controls and POP. We did not find it possible to use the HL and ML for the sitting position; the HL extends from the most inferior surface of the pubis to the posterior wall of the anal canal at the level of the anorectal junction, and ML is drawn as a vertical line extending perpendicularly from PCL to the posterior end of the H line. The effect of the sitting position is to cause an upwards movement of anorectal junction location above the PCL, which interferes with measurement using both these reference lines.

The grading of symptomatic subjects for POP from images obtained using MRO in the standing and supine positions are summarized in Tables 5 and 6; the PCL reference line (Fig.7) was used to grade POP, (cystocele, vaginal prolapse, and rectal prolapse), as absent, mild, moderate or severe. The occurrence of prolapse in the anterior and posterior compartments in the standing position was moderately higher than in the anterior and middle compartments in both positions.

Our results suggest that the extent of prolapse is best evaluated in the standing position using HL, ML, MPL, and PL as reference lines.

\section{Discussion}

In this study, we have used MRO images obtained with patients standing, sitting, and supine to quantify the extent of POP using pelvic reference lines. We hypothesized that imaging in the standing and sitting position would identify prolapse not apparent in the supine position in patients reporting symptoms of POP, as the effect of posture and gravity on pelvic organ position would be detected. Currently, POP is assessed on midsagittal images using particular pelvic anatomic landmarks ${ }^{35}$ and quantified and graded using reference lines. ${ }^{36}$ In the literature, various reference lines have been introduced to assess POP during dynamic MRI. However, validation of 
these reference lines is lacking. ${ }^{17}$ Hence, in this study we made used of multiple lines for comparison (PCL, SCIPP, PP, HL, ML, MPL, and PL).

Our data indicate that in standing MRO images the extent of descent of POP in all three compartments was greater than that seen in supine images, when the PCL, HL, ML, MPL, and PL were used for reference; hence standing position does provide a more comprehensive way of detecting POP and defining the extent of prolapse than any of the existing imaging tools, including conventional supine MRI, as the extent of descent of POP in all three compartments was greater when assessed using the HL, ML, MPL, and PL for reference. This confirms previous findings that the frequency of detection of anterior and posterior compartment downward prolapse can be best assessed when using MRO in the standing position. We have also reported the enhanced diagnostic information generated by creating 3D models of the pelvic architecture from 2D MRO upright imaging. ${ }^{37}$

However, imaging in the sitting position did not demonstrate benefit in the context of POP. This was principally due to anatomical landmarks necessary for defining the HL and ML reference lines being obscured by upward movement of the anorectal junction above the PCL. While our hypothesis was only true for standing images, sitting MRO images could benefit POP evaluation in symptomatic patients confined to wheelchairs, such as those with spinal cord injury, even though the information added is less than from standing images.

In prior studies, compared dynamic MR imaging and colpocystodefecography (CCD) in the diagnosis of prolapse in each compartment. ${ }^{38}$ Their results concluded that dynamic MR imaging in the lying orientation was not precise in the assessment of pelvic floor prolapse. ${ }^{17}$ In contrast, a study done by Swift et al. ${ }^{26}$ reported no significant difference in prolapse grading between supine and standing positions. Another study reported that a higher extent of prolapse was observed in the standing orientation as compared with the supine examination, although another finding did not show this relationship. ${ }^{22,26}$ However, the effects of bladder fullness and patient posture have not been formerly examined. ${ }^{25}$

The optimal choice of reference line is a subject of ongoing debate. ${ }^{17}$ The PCL is commonly used because it is readily drawn on sagittal images ${ }^{21}$ and was used in initial studies of MRI for POP because it is based on fixed bony points of reference. ${ }^{18}$ The PCL also provides an assessment of the pelvic floor, as it is positioned along the plane of the pubococcygeal and puborectalis muscles. ${ }^{21}$ Lienemann et al. found the PCL was a beneficial reference line for prolapse in the anterior compartment only; ${ }^{28}$ however, Pannu et al. ${ }^{39}$ described the PCL to be superior. In our study we found no significant change in the length for the supine and the sitting positions between the two groups. However, the mean length of the PCL in the standing position was significantly different between the groups.

Lienemann et al. also used the mid-pubic line in their study and reported that the midpubic line should only be applied for staging in the posterior compartment. ${ }^{28}$ Singh et al. ${ }^{40}$ introduced the application of the MPL on MRI grading of POP. They concluded, upon cadaveric dissection, that the MPL passing through the plane of the vaginal hymen should be used in 
clinical examination. However, two different studies defined poor correlation between clinical assessment and dynamic MRI, ${ }^{14,31}$ and some authors have uncertainty about the validity of this line to represent the hymenal level in vivo during maximum strain. ${ }^{14}$ An inconvenient aspect of using the MPL for grading POP is that two separate measurements are needed: at rest and during strain. ${ }^{30,41}$ Importantly, in previous studies Woodfield et al. ${ }^{18}$ and Singh et al. ${ }^{40}$ found that the MPL yielded a much greater frequency of prolapse than the PCL, and our findings indicate that the MPL and PL measurements were significantly different between the control and the patient group for the standing and supine positions.

The SCIPP line has been used to quantify the distance to the perineal body and the angle of the levator plate when comparing women without prolapse and POP patients, grading anterior vaginal wall prolapse, and assessing levator ani recovery following vaginal birth. ${ }^{42}$ However, the data we present indicate that for the SCIPP line the increase in length between the control group and POP patients was statically significant in the standing position but not in the supine or sitting positions.

Comiter et al. ${ }^{15}$ introduced a new grading system for dynamic MRI scanning. The $\mathrm{H}$ line, M line, organ prolapse (HMO) classification system assesses the levator hiatus (LH), the muscular pelvic floor movement downward, and organ descent. ${ }^{19}$ MRI and ultrasound studies have demonstrated that a levator ani muscle defect is a significant factor that is clinically related to POP. ${ }^{43}$ It is reported that patients with prolapse have enlarged genital hiatuses. ${ }^{44}$ This hiatal enlargement might be either the reason for or the outcome of prolapse. Defects and weakening of the levator ani muscle, as observed in prolapse, could lead to inability to keep the hiatus closed. ${ }^{43}$ The length of the levator hiatus $\mathrm{H}$ line is $5 \mathrm{~cm}$ in normal women without pelvic floor laxity. ${ }^{45}$ The $\mathrm{M}$ line is a line that extends perpendicularly from PCL to the posterior end of $\mathrm{H}$ line, and an average length of $2 \mathrm{~cm}$ is considered normal. ${ }^{32}$

Dietz et al. ${ }^{46}$ concluded that there is an association between LH and pelvic organ displacement, even in young nulliparous women. Likewise, a study by DeLancey and Hurd ${ }^{44}$ also reported that uroginal hiatus size is related to prolapse size. ${ }^{47}$ In this study, MRO images displayed significant elongation in dimensions of $\mathrm{H}$ and $\mathrm{M}$ lines that was seen in all POP patients in standing and supine positions but not in the control group.

We recognize that the ongoing debate over reference lines applied to MRI is a limitation that impacts our study. It remains hard to choose which pelvic reference lines would supply the best reference landmark for the MRO assessments of POP. But further MRO studies are required and are pending. In this context the fact that few MRO systems are available currently for patient assessment also limits the relevance of our findings. However, the apparent superiority of MRO as an imaging entity for POP predicates that as more units become available clinicians and their patients should benefit from this advance in technology.

\section{Conclusion}

In conclusion, using MRO to image patients with symptoms of POP in an upright position shows that greater levels of downward movement in the anterior and posterior compartments, labeled as 
cyctocele and rectocele, occur under the influence of posture and gravity. The maximal extent of downward movement is best evaluated in the standing position; use of the HL, ML, MPL, and PL reference lines most readily identified downward prolapse, while organ position in the sitting position precluded use of the HL and ML lines. We suggest that as access to MRO becomes available benefits will accrue from the enhanced diagnostic and grading ability of upright imaging in POP. 


\section{References}

1. Ren S, Xie B, Wang J, et al. Biomechanics of pelvic organ prolapse. Sci China Life Sci 2015;58:218-20.

2. DeLancey JO. Functional anatomy of the female lower urinary tract and pelvic floor. Ciba Found Symp 1990;151:57-69; discussion 69-76.

3. Frawley HC, Galea MP, Phillips BA, et al. Reliability of pelvic floor muscle strength assessment using different test positions and tools. Neurourol Urodyn 2006;25:236-42.

4. Bo K. Can pelvic floor muscle training prevent and treat pelvic organ prolapse? Acta Obstet Gynecol Scand 2006;85:263-8.

5. Bump RC, Norton PA. Epidemiology and natural history of pelvic floor dysfunction. Obstet Gynecol Clin North Am 1998;25:723-46.

6. Abrams P, Cardozo L, Fall M, et al. The standardisation of terminology of lower urinary tract function: Report from the Standardisation Sub-committee of the International Continence Society. Am J Obstet Gynecol 2002;187:116-26.

7. Healy JC, Halligan S, Reznek RH, et al. Patterns of prolapse in women with symptoms of pelvic floor weakness: Assessment with MR imaging. Radiology 1997:203:77-81.

8. Kelvin FM, Maglinte DD. Dynamic cystoproctography of female pelvic floor defects and their interrelationships. AJR Am J Roentgenol 1997;169:769-74.

9. Maglinte DD, Kelvin FM, Fitzgerald K, et al. Association of compartment defects in pelvic floor dysfunction. AJR Am J Roentgenol 1999;172:439-44.

10. Stoker J, Halligan S, Bartram CI. Pelvic floor imaging. Radiology 2001:218:621-41.

11. Bump RC, Mattiasson A, Bø K, et al. The standardization of terminology of female pelvic organ prolapse and pelvic floor dysfunction. Am J Obstet Gynecol 1996;175:10-7.

12. Haylen BT,Maher CF, Barber MD, et al. An International Urogynecological Association (IUGA) / International Continence Society (ICS) joint report on the terminology for female pelvic organ prolapse (POP). Int Urogynecol J 2016;27:165-94.

13. Altman D, López A, Kierkegaard J, et al. Assessment of posterior vaginal wall prolapse: Comparison of physical findings to cystodefecoperitoneography. Int Urogynecol J Pelvic Floor Dysfunct 2005;16:96-103; discussion 103.

14. Fauconnier A, Zareski E, Abichedid J, et al. Dynamic magnetic resonance imaging for grading pelvic organ prolapse according to the International Continence Society classification: Which line should be used? Neurourol Urodyn 2008;27:191-7.

15. Comiter CV, Vasavada SP, Barbaric ZL, et al. Grading pelvic prolapse and pelvic floor relaxation using dynamic magnetic resonance imaging. Urology 1999;543:454-7.

16. Lienemann A, Anthuber C, Baron A, et al. Dynamic MR colpocystorectography assessing pelvic-floor descent. Eur Radiol 1997;7:1309-17.

17. Broekhuis SR, Fütterer JJ, Barentsz JO, et al. A systematic review of clinical studies on dynamic magnetic resonance imaging of pelvic organ prolapse: The use of reference lines and anatomical landmarks. Int Urogynecol J Pelvic Floor Dysfunct 2009;20:721-9.

18. Woodfield CA, Hampton BS, Sung V, et al. Magnetic resonance imaging of pelvic organ prolapse: Comparing pubococcygeal and midpubic lines with clinical staging. Int Urogynecol J Pelvic Floor Dysfunct 2009;20(6):695-701.

19. Koduri S, Sand PK. Recent developments in pelvic organ prolapse. Curr Opin Obstet Gynecol 2000;12:399-404. 
20. Friedman B, Stothers L, D. Lazare D, Macnab AJ. Positional pelvic organ prolapse (POP) evaluation using open, weight-bearing magnetic resonance imaging (MRI). Can Urol Assoc J, 2015; 9:197-200.

21. Yang A, Mostwin JL, Rosenshein NB, et al. Pelvic floor descent in women: Dynamic evaluation with fast MR imaging and cinematic display. Radiology 1991;179:25-33.

22. Barber MD, Lambers A, Visco AG, et al. Effect of patient position on clinical evaluation of pelvic organ prolapse. Obstet Gynecol 2000;96:18-22.

23. Hall AF, Theofrastous JP, Cundiff GW, et al. Interobserver and intraobserver reliability of the proposed International Continence Society, Society of Gynecologic Surgeons, and American Urogynecologic Society pelvic organ prolapse classification system. Am J Obstet Gynecol 1996;175:1467-70; discussion 1470-1.

24. Visco AG, Wei JT, McClure LA, et al. Effects of examination technique modifications on pelvic organ prolapse quantification (POP-Q) results. Int Urogynecol J Pelvic Floor Dysfunct 2003;14:136-40.

25. Silva WA, Kleeman S, Segal J, et al. Effects of a full bladder and patient positioning on pelvic organ prolapse assessment. Obstet Gynecol 2004;104:37-41.

26. Swift SE,Herring M. Comparison of pelvic organ prolapse in the dorsal lithotomy compared with the standing position. Obstet Gynecol 1998;91:961-4.

27. Morren GL, Balasingam AG, Wells JE, et al. Triphasic MRI of pelvic organ descent: Sources of measurement error. Eur J Radiol 2005;54:276-83.

28. Lienemann A, Sprenger D, Janssen U, et al. Assessment of pelvic organ descent by use of functional cine-MRI: Which reference line should be used? Neurourol Urodyn 2004;23:33-7.

29. Boyadzhyan L, Raman SS,Raz S. Role of static and dynamic MR imaging in surgical pelvic floor dysfunction. Radiographics 2008;28:949-67.

30. Broekhuis SR, Kluivers KB, Hendriks, JC, et al, Dynamic magnetic resonance imaging: Reliability of anatomical landmarks and reference lines used to assess pelvic organ prolapse. Int Urogynecol J Pelvic Floor Dysfunct 2009;20:141-8.

31. Cortes E, Reid WM, Singh K, et al. Clinical examination and dynamic magnetic resonance imaging in vaginal vault prolapse. Obstet Gynecol 2004;103:41-6.

32. Hoyte L, Schierlitz L, Zou K, et al. Two- and 3-dimensional MRI comparison of levator ani structure, volume, and integrity in women with stress incontinence and prolapse. Am J Obstet Gynecol 2001;185:11-9.

33. Nardos R, Thirmond AS, Worstell TR, et al. Reference lines in dynamic magnetic resonance imaging of the pelvic floor. Female Pelvic Med Reconstr Surg 2010;16:242-5.

34. Lakeman MM, Zijta FM, Peringa J, et al. Dynamic magnetic resonance imaging to quantify pelvic organ prolapse: Reliability of assessment and correlation with clinical findings and pelvic floor symptoms. Int Urogynecol J 2012;23:1547-54.

35. Woodfield CA, Krishnamoorthy S, Hampton BS, et al. Imaging pelvic floor disorders: Trend toward comprehensive MRI. AJR Am J Roentgenol 2010;194:1640-9.

36. Ginath S, Garely A, Luchs JS, et al. MRI pelvic landmark angles in the assessment of apical pelvic organ prolapse. Arch Gynecol Obstet 2011;284:365-70.

37. Abdulaziz M, Stothers L, Macnab AJ Methodology for 3D image reconstruction of the female pelvis from upright open MRI (MRO) imaging. Biomedical Spectroscopy and Imaging 2018 (in press) 
38. Gousse AE, Barbaric ZJ, Safir MK, et al. Dynamic half Fourier acquisition, single shot turbo spin-echo magnetic resonance imaging for evaluating the female pelvis. $J$ Urol 2000;164:1606-13.

39. Pannu HK, Scatarige, JC, Eng J. MRI diagnosis of pelvic organ prolapse compared with clinical examination. Acad Radiol 2011;18:1245-51.

40. Singh K, Reid WM, Berger LA. Assessment and grading of pelvic organ prolapse by use of dynamic magnetic resonance imaging. Am J Obstet Gynecol 2001;185:71-7.

41. Pizzoferrato AC, Nyangoh Timoh K, Fritel X, et al. Dynamic magnetic resonance imaging and pelvic floor disorders: How and when? Eur J Obstet Gynecol Reprod Biol 2014;181:259-66.

42. Hsu Y, Summers A, Hussain HK, et al. Levator plate angle in women with pelvic organ prolapse compared to women with normal support using dynamic MR imaging. Am J Obstet Gynecol 2006;194:1427-33.

43. DeLancey JO, Morgan DM, Fenner DE, et al. Comparison of levator ani muscle defects and function in women with and without pelvic organ prolapse. Obstet Gynecol 2007;109:295-302.

44. Delancey JO, Hurd WW. Size of the urogenital hiatus in the levator ani muscles in normal women and women with pelvic organ prolapse. Obstet Gynecol 1998;91:364-8.

45. Macura KJ. Magnetic resonance imaging of pelvic floor defects in women. Top Magn Reson Imaging 2006;17:417-26.

46. Dietz HP, Shek C, Clarke B. Biometry of the pubovisceral muscle and levator hiatus by three-dimensional pelvic floor ultrasound. Ultrasound Obstet Gynecol 2005;25:580-5.

47. Clark NA, Brincat CA, Yousuf AA, et al. Levator defects affect perineal position independently of prolapse status. Am J Obstet Gynecol 2010;203:595 e17-22. 


\section{Figures and Tables}

Fig. 1. Open magnetic resonance imaging. The open magnetic resonance imaging unit is shown in position to scan the pelvic floor with the patient $(\boldsymbol{A})$ supine; $(\boldsymbol{B})$ sitting; and $(\boldsymbol{C})$ standing. The scanner's safety straps are shown across the abdomen to secure the patient.
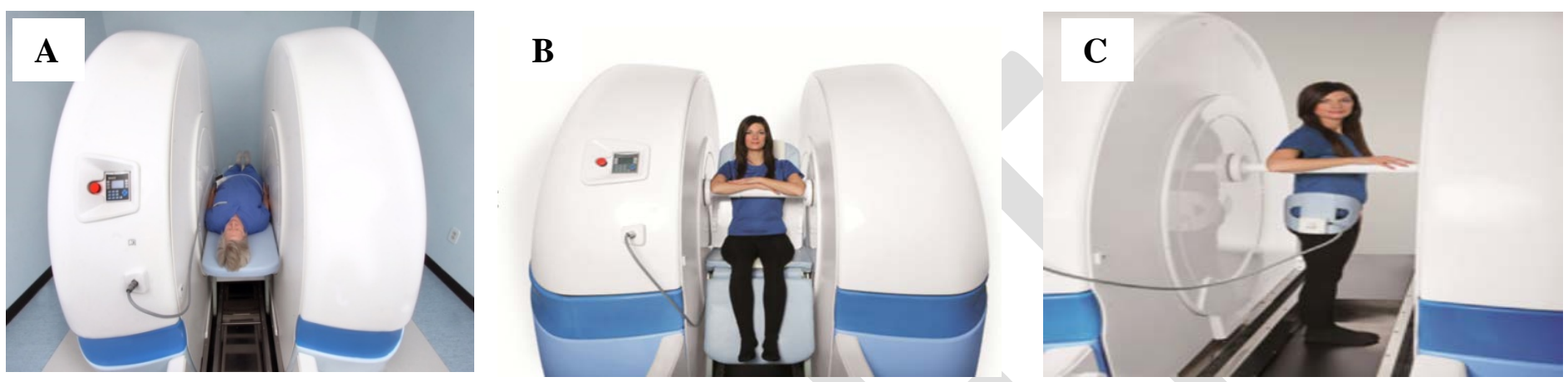

Fig. 2. A patient in the standing position of open magnetic resonance imaging (MRO) examination with a compression cuff around each leg.

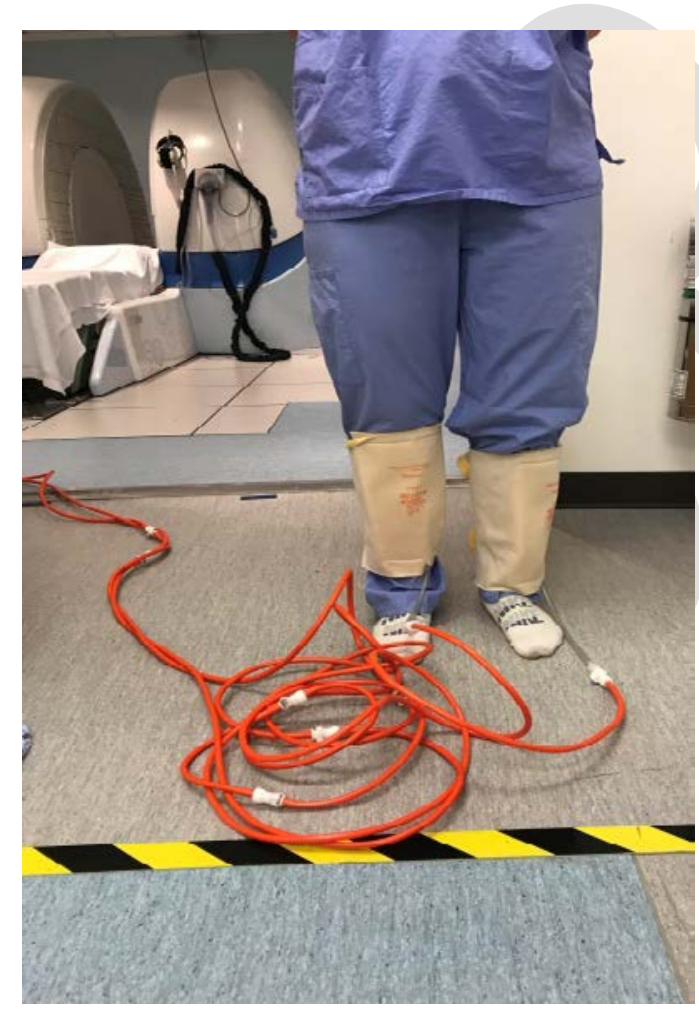

Fig. 3. Sagittal T2-weighted midline views of the female pelvis in a 51-year-old symptomatic subject demonstrating evidence of pelvic organ prolapse (POP) when the patient is imaged 
standing. The 3 images: $(\boldsymbol{A})$ supine; $(\boldsymbol{B})$ sitting; and $(\boldsymbol{C})$ standing show the pelvic reference lines (PCL, SCIPP, PP, HL, ML, MPL, and ML) used in the diagnosis of POP.
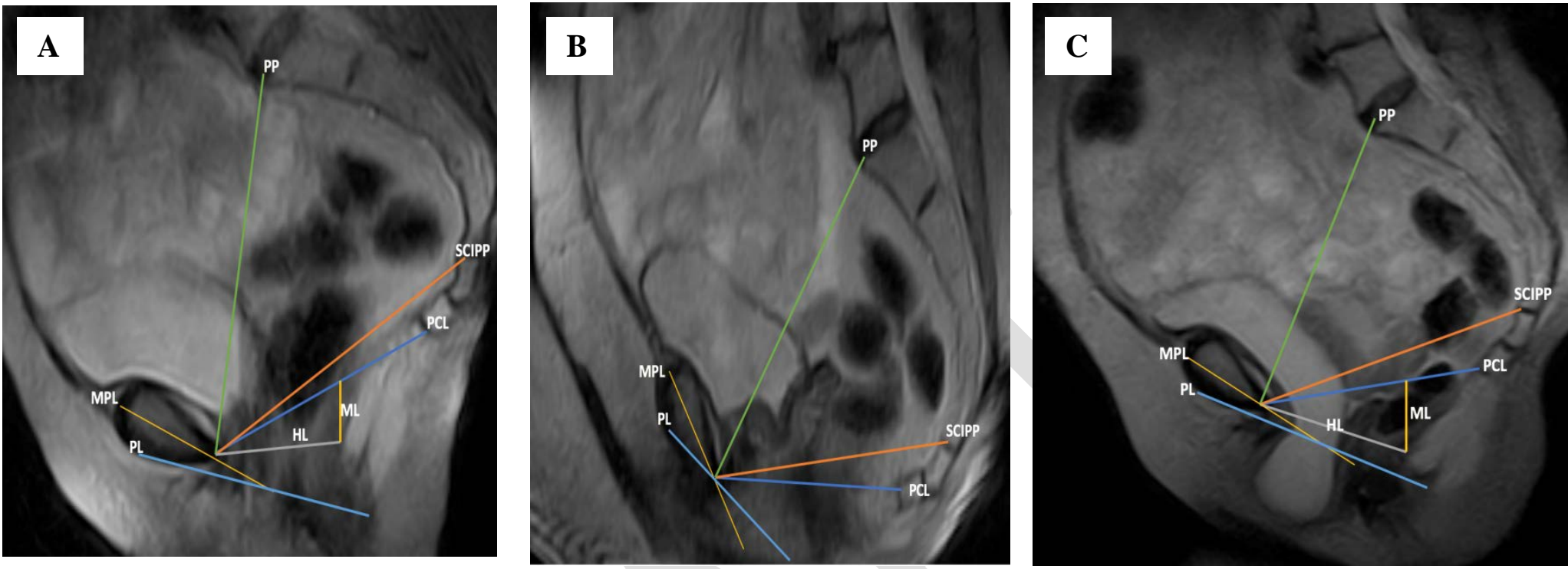

Fig. 4. Sagittal open magnetic resonance imaging midline views of the female pelvis obtained in the standing position (with reference lines) showing in $(A)$ no evidence of pelvic organ prolapse (POP) in a 26-year-old control (asymptomatic) subject; and (B) the presence of POP in a 56year-old symptomatic subject with cyctocele evident in her midsagittal T2 image.
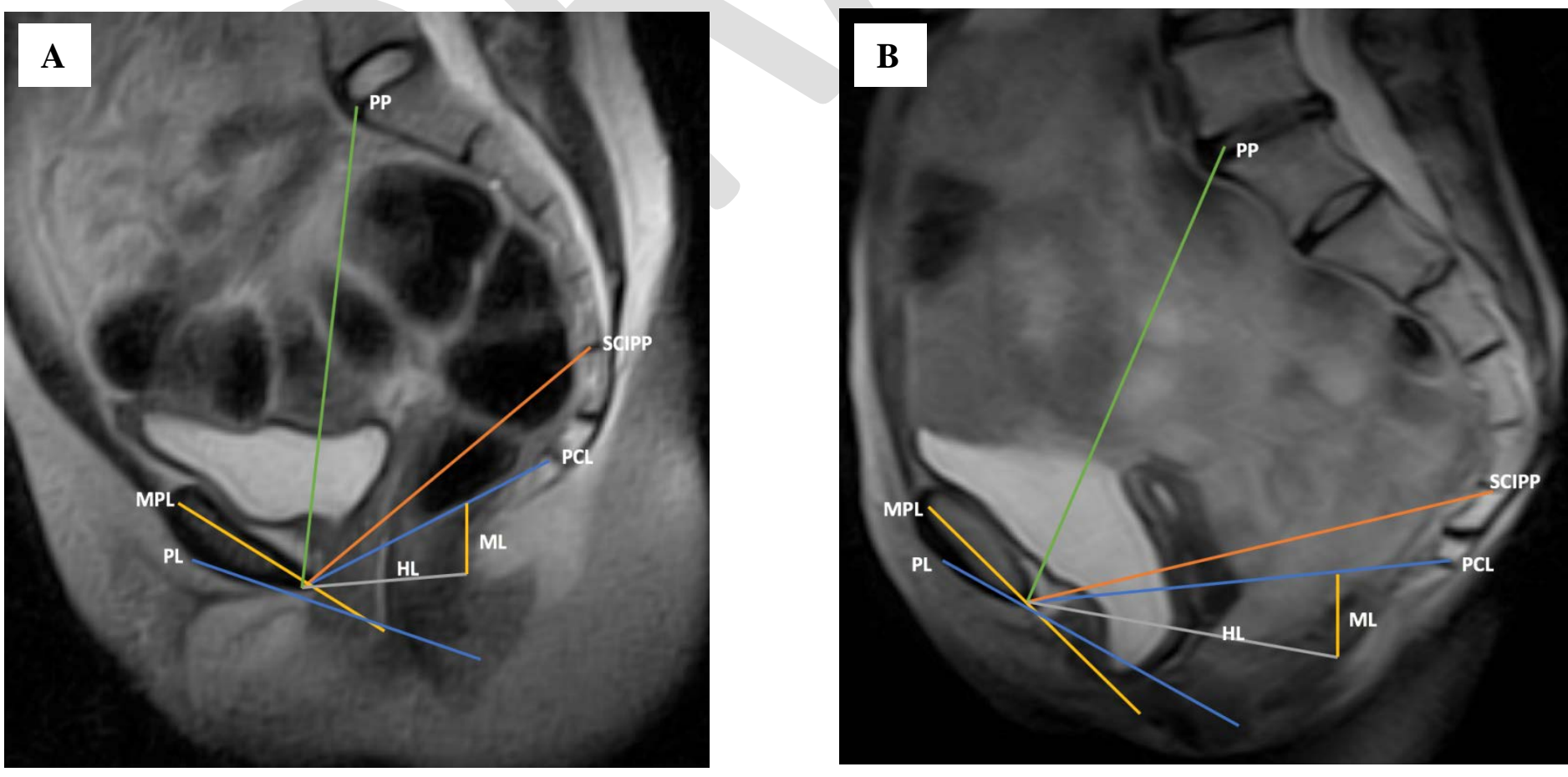
Fig. 5. Sagittal open magnetic resonance imaging midline views of the female pelvis obtained in the supine position: (A) Midsagittal T2-weighted image of a 27-year-old control subject with measurement of reference line lengths; $(\boldsymbol{B})$ Midsagittal T2-weighted image of a 66-year-old control subject with measurement of reference line lengths.
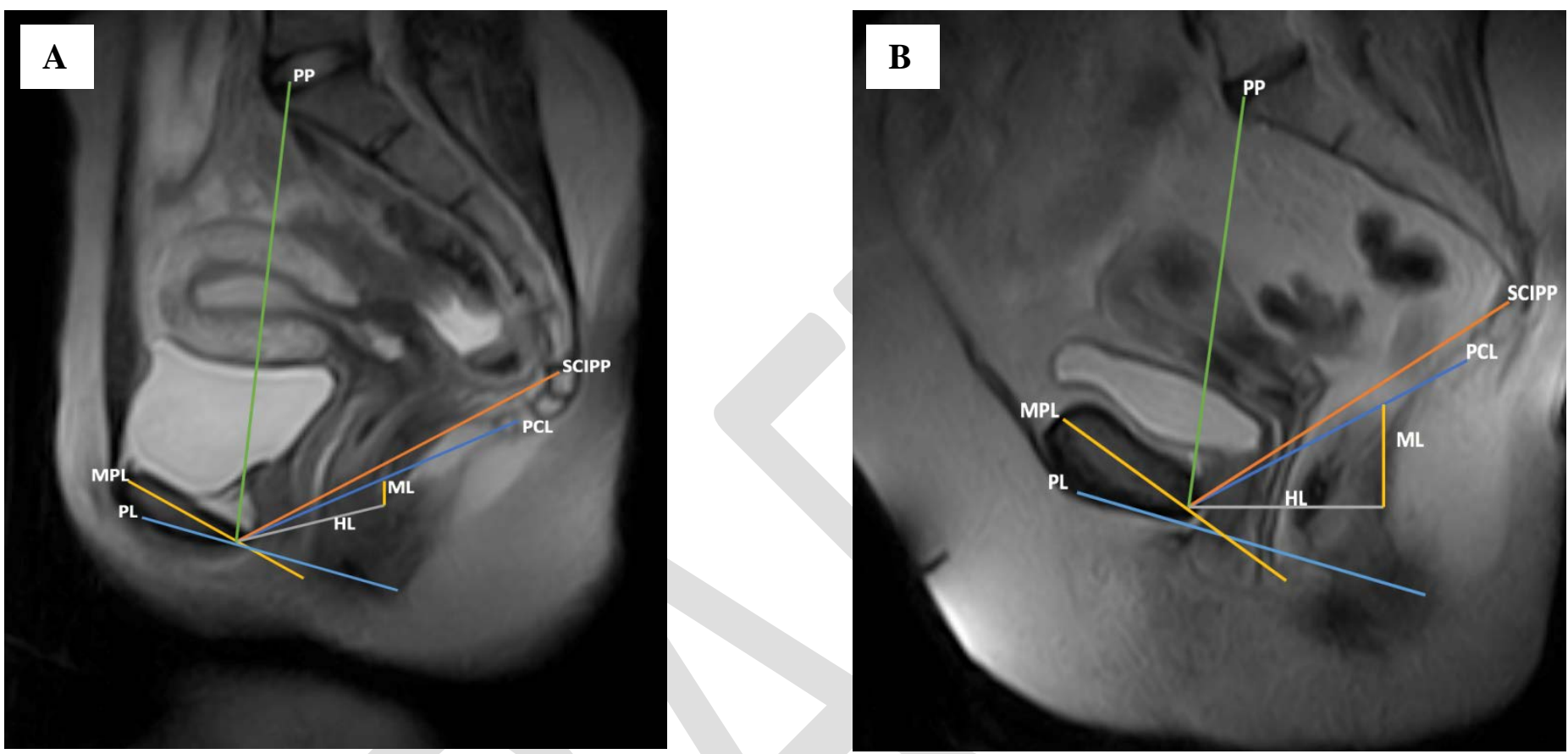

Fig. 6. Sagittal open magnetic resonance imaging midline views of the female pelvis obtained in the sitting position: (A) A 27-year-old control subject midsagittal T2-weighted image showing measurements of reference lines; (B) A 51-year-old symptomatic subject midsagittal T2weighted image showing measurements of reference lines.
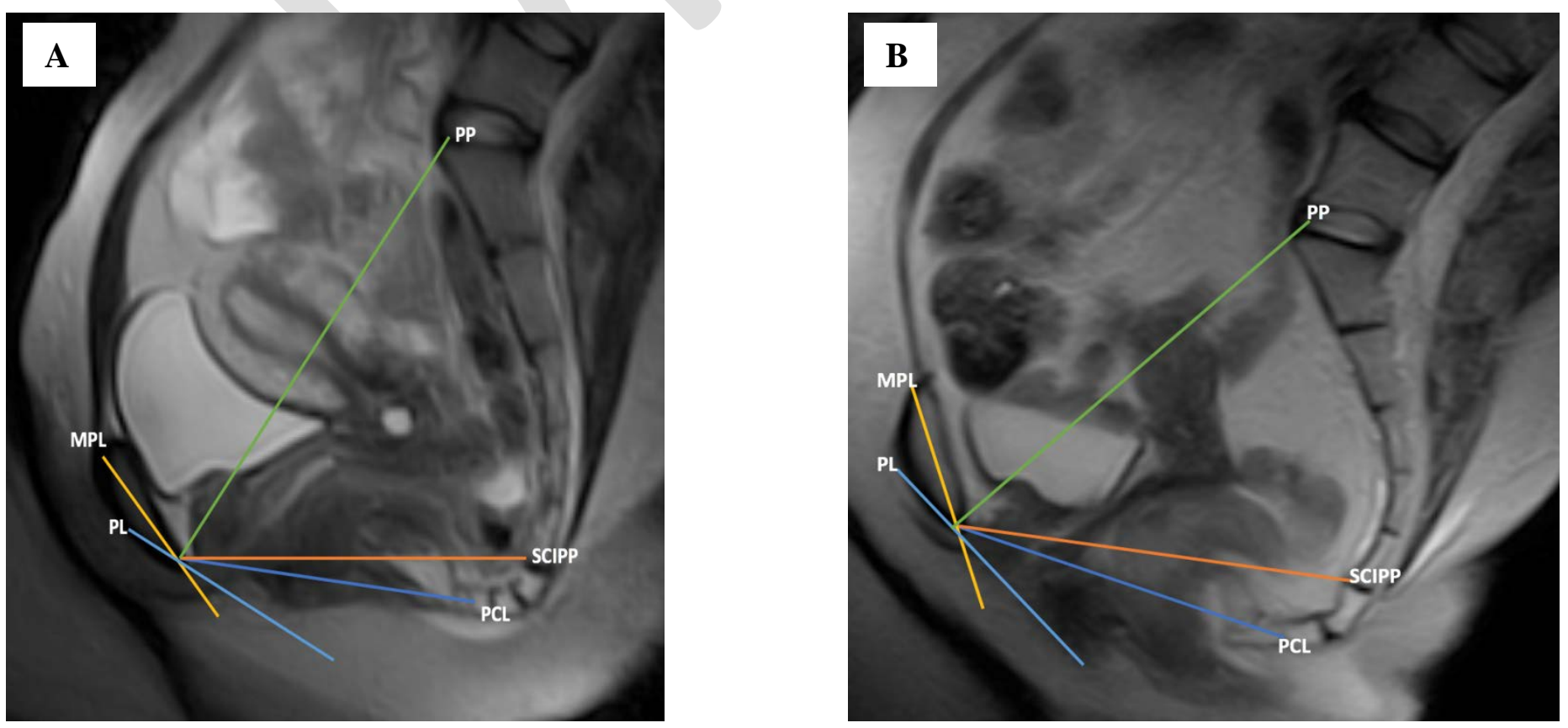
Fig. 7. The perpendicular distances from the pubococcygeal reference line (PCL) to the bladder base, vaginal apex, and anorectal junction, which were applied to grade the degree of downward descent in the anterior $(\mathrm{A})$, middle $(\mathrm{M})$, and posterior $(\mathrm{P})$ compartments, respectively: $(\mathrm{A})$ standing position; and $(\boldsymbol{B})$ supine position.
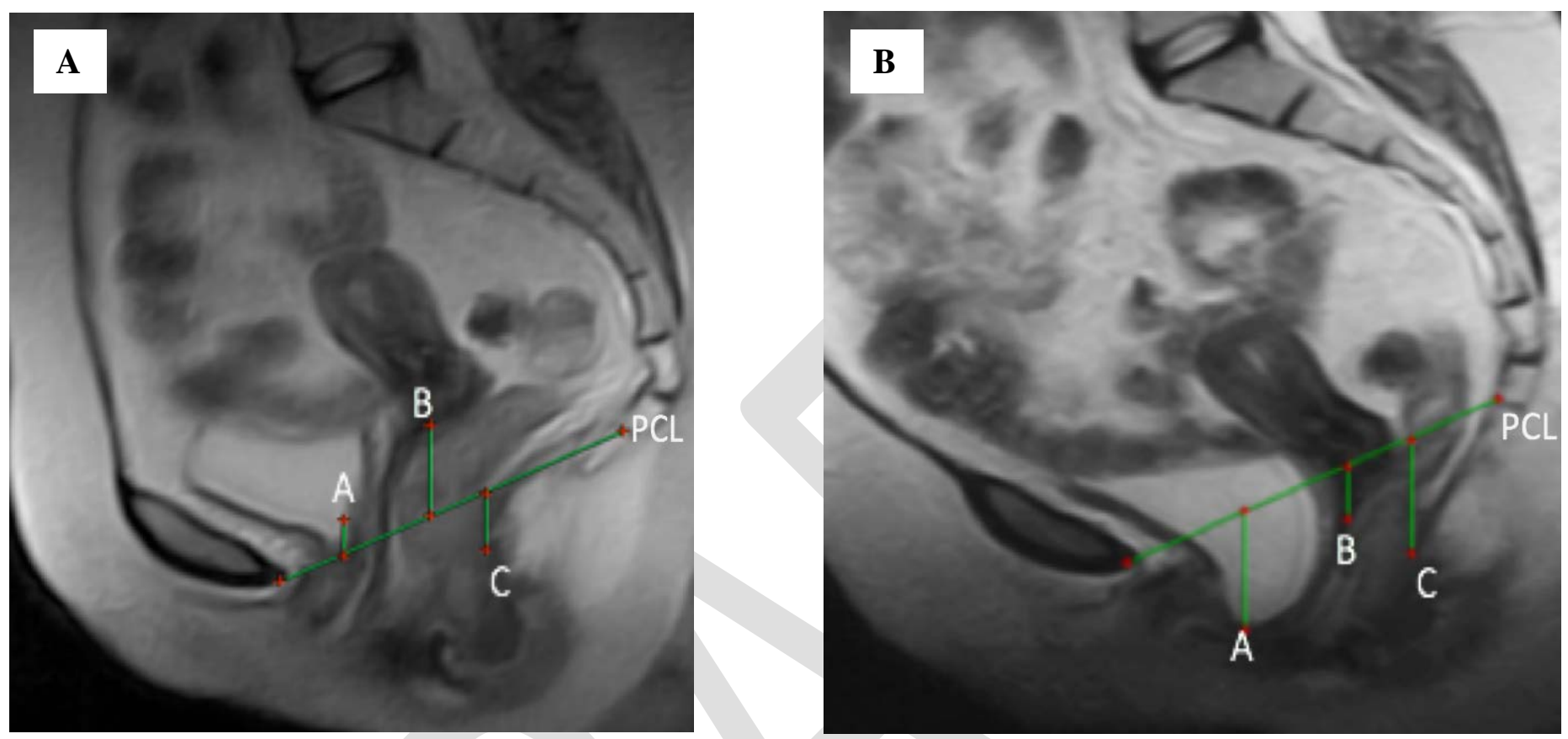

Table 1. Summary of clinical data on the 20 symptomatic subjects

\begin{tabular}{|l|c|c|c|c|c|c|}
\hline Subject & $\begin{array}{c}\text { Age } \\
\text { (years) }\end{array}$ & Pregnancy & Delivery & Prior surgery & Symptoms & $\begin{array}{c}\text { Body } \\
\text { mass } \\
\text { index }\end{array}$ \\
\hline 1 & 53 & 1 & Vaginal & No & Incontinence & 22 \\
\hline 2 & 48 & 3 & Vaginal & No & Urinary frequency & 26.3 \\
\hline 3 & 65 & 1 & Vaginal & No & Urinary frequency & 19.5 \\
\hline 4 & 53 & 2 & Vaginal & No & Protrusion & 22.6 \\
\hline 5 & 51 & 4 & Vaginal & Hysterectomy & Incontinence & 29.8 \\
\hline
\end{tabular}




\begin{tabular}{|l|c|c|c|c|c|c|}
\hline 6 & 46 & 4 & Vaginal & No & Frequent UTI & 25.1 \\
\hline 7 & 56 & 3 & Vaginal & No & Protrusion & 26.8 \\
\hline 8 & 61 & 2 & Vaginal & Mastectomy & Protrusion & 26 \\
\hline 9 & 54 & 3 & C- section & No & Urinary frequency & 32.5 \\
\hline 10 & 51 & 3 & Vaginal & Mastectomy & $\begin{array}{c}\text { Incomplete bladder } \\
\text { emptying }\end{array}$ & 30.8 \\
\hline 11 & 52 & 2 & Vaginal & No & Constipation & 23.7 \\
\hline 12 & 46 & 2 & Vaginal & $\begin{array}{c}\text { Dilation and } \\
\text { curettage }\end{array}$ & Frequency-urgency & 19.3 \\
\hline 13 & 72 & 5 & Vaginal & No & Incontinence & 35.5 \\
\hline 14 & 76 & 3 & Vaginal & No & Incontinence & 29.8 \\
\hline 15 & 77 & 1 & Vaginal & Hysterectomy & Incontinence & 25 \\
\hline 16 & 43 & 2 & Vaginal & No & Urinary leakage & 19.1 \\
\hline 17 & 63 & 2 & Vaginal & No & Incontinence & 30.5 \\
\hline 18 & 73 & 2 & Vaginal & No & Incontinence & 24.1 \\
\hline 19 & 73 & 2 & Vaginal & No & Protrusion & 25.6 \\
\hline 20 & 61 & 3 & Vaginal & No & Stress incontinence & 27.3 \\
\hline
\end{tabular}


Table 2. Comparison of data from pelvic reference line length $(\mathrm{cm})$ between subjects symptomatic for POP and the control group obtained in the STANDING position

\begin{tabular}{|l|c|c|c|c|}
\hline Lines & $\begin{array}{c}\text { Mean } \\
\text { difference of } \\
\text { control group } \\
\text { in cm (n=20) }\end{array}$ & $\begin{array}{c}\text { Mean } \\
\text { difference of } \\
\text { POP group in } \\
\mathbf{c m} \text { (n=20) }\end{array}$ & SD & p \\
\hline PCL & 9.96 & 10.83 & 0.61 & 0.005886954 \\
\hline SCIPP & 11.80 & 12.58 & 0.55 & 0.013283919 \\
\hline PP & 13.92 & 13.65 & 0.18 & 0.409461995 \\
\hline HL & 5.79 & 7.80 & 1.42 & 0.00000002 \\
\hline ML & 1.79 & 3.54 & 1.23 & 0.00000085 \\
\hline MPL & 7.36 & 9.56 & 1.55 & 0.00000007 \\
\hline PL & 8.19 & 10.89 & 1.91 & 0.00000001 \\
\hline
\end{tabular}

p $<0.05$. HL: H line; ML: M line; MPL: mid-pubic line; PCL: pubococcygeal line; PL: perineal line; POP: pelvic organ prolapse; PP: pubopromontoreal ; SD: standard deviation.

Table 3. Comparison of data from pelvic reference line length $(\mathrm{cm})$ between subjects symptomatic for POP and the control group obtained in the SUPINE position

\begin{tabular}{|l|c|c|c|c|}
\hline Lines & $\begin{array}{c}\text { Mean } \\
\text { difference of } \\
\text { control group } \\
\text { in cm (n=20) }\end{array}$ & $\begin{array}{c}\text { Mean } \\
\text { difference of } \\
\text { POP group in } \\
\mathbf{c m}(\mathbf{n}=\mathbf{2 0})\end{array}$ & SD & p \\
\hline PCL & 9.72 & 10.34 & 0.44 & 0.06028385 \\
\hline SCIPP & 11.66 & 12.07 & 0.29 & 0.20369371 \\
\hline PP & 14.34 & 13.77 & 0.41 & 0.03956687 \\
\hline HL & 4.87 & 6.11 & 0.88 & 0.00000155 \\
\hline ML & 1.45 & 2.12 & 0.47 & 0.00008880 \\
\hline MPL & 6.57 & 7.70 & 0.80 & 0.00015362 \\
\hline PL & 7.12 & 8.97 & 1.30 & 0.00006763 \\
\hline
\end{tabular}

p $<0.05$. HL: $H$ line; ML: M line; MPL: mid-pubic line; PCL: pubococcygeal line; PL: perineal line; POP: pelvic organ prolapse; PP: pubopromontoreal ; SD: standard deviation. 
Table 4. Comparison of data from pelvic reference line length $(\mathrm{cm})$ between subjects symptomatic for POP and the control group obtained in the sitting position

\begin{tabular}{|l|c|c|c|c|}
\hline Lines & $\begin{array}{c}\text { Mean } \\
\text { difference of } \\
\text { control group } \\
\text { in cm (n=20) }\end{array}$ & $\begin{array}{c}\text { Mean } \\
\text { difference of } \\
\text { POP group in } \\
\mathbf{c m}(\mathbf{n}=\mathbf{2 0})\end{array}$ & SD & p \\
\hline PCL & 10.34 & 10.69 & 0.23 & 0.30 \\
\hline SCIPP & 12.34 & 12.38 & 0.03 & 0.90 \\
\hline PP & 14.21 & 13.56 & 0.46 & 0.04 \\
\hline MPL & 6.61 & 6.78 & 0.12 & 0.44 \\
\hline PL & 7.45 & 7.66 & 0.15 & 0.53 \\
\hline
\end{tabular}

p< 0.05. MPL: mid-pubic line; PCL: pubococcygeal line; PL: perineal line; POP: pelvic organ prolapse; PP: pubopromontoreal ; SD: standard deviation.

\begin{tabular}{|l|c|c|c|c|}
\hline \multicolumn{6}{|l|}{$\begin{array}{l}\text { Table 5. Detection of POP in MRO standing images from the } \\
\text { symptomatic subjects using reference line parameters }\end{array}$} \\
\hline PCL & Absent (\%) & Mild (\%) & Moderate (\%) & $\begin{array}{c}\text { Severe } \\
\text { (\%) }\end{array}$ \\
\hline Cyctocele & 10 & 50 & 30 & 10 \\
\hline $\begin{array}{l}\text { Vaginal } \\
\text { prolapse }\end{array}$ & 45 & 35 & 20 & 0 \\
\hline Rectocele & 0 & 10 & 80 & 10 \\
\hline
\end{tabular}

MRO: open magnetic resonance imaging; PCL: pubococcygeal line; POP: pelvic organ prolapse.

\begin{tabular}{|l|c|c|c|c|}
\hline \multicolumn{6}{|l|}{$\begin{array}{l}\text { Table 6. Detection of POP in MRO supine images from the } \\
\text { symptomatic subjects using reference line parameters }\end{array}$} \\
\hline PCL & Absent (\%) & Mild (\%) & Moderate (\%) & $\begin{array}{c}\text { Severe } \\
\text { (\%) }\end{array}$ \\
\hline Cyctocele & 95 & 5 & 0 & 0 \\
\hline $\begin{array}{l}\text { Vaginal } \\
\text { prolapse }\end{array}$ & 75 & 25 & 0 & 0 \\
\hline Rectocele & 0 & 55 & 40 & 5 \\
\hline
\end{tabular}

MRO: open magnetic resonance imaging; PCL: pubococcygeal line; POP: pelvic organ prolapse. 